\title{
Oxidation of ODS alloys (*)
}

\author{
W.J. Quadakkers
}

Research Centre Jülich, Institute for Reactor Materials, P.O. Box 19 13, 5170 Jülich, Germany

\begin{abstract}
NiCr, NiCrAl and FeCrAl based Oxide Dispersion Strengthened (ODS) high tem perature alloys possess far better oxidation resistance than dispersion free alloys of the same base composition. The presence of yttria dispersions leads to excellent scale adherence and a very selective oxidation of the scale forming element. Most of the observed differences in microstructure and protective properties between oxide scales on ODS and non-ODS alloys can be explained by differences in scale transport mechanisms. Although other dispersions have been found to have a positive effect on oxidation behaviour similar to that of yttria, they seem to possess no major advantage, provided that the yttria content is properly adjusted to the actual alloy system.
\end{abstract}

\section{Introduction.}

The demand for increased efficiency of processes in chemical engineering and energy conversion in many cases requires metallic materials which allow plant or engine components being designed to operate at high temperatures, often at high stresses in corrosive environments. The presently used high temperature $\mathrm{Ni}$, Co and Fe based alloys are strengthened by a combination of solid solution and precipitation hardening, the effectiveness of which strongly decreases at higher temperatures. ODS alloys $[1,2]$ contain small amounts $(\sim 0.5$ $1 \mathrm{wt} .-\%$ ) of a finely dispersed oxide phase (mostly yttria) which is thermodynamically much more stable than the strengthening precipitates, such as "gamma prime" $\left(\gamma^{\prime}\right)$ and carbides, present in conventional high temperaure alloys. Therefore, the strengthening imparted by the oxide dispersions is retained up to very high temperatures because only limited coarsening or dissolution of the particles occurs. In addition, the presence of the dispersions allows the stabilization of a very coarse grained microstructure over long exposure times [2-4] which leads to excellent creep resistance up to higher temperatures than can be achieved with conventional wrought or cast alloys.

ODS alloys are produced by high energy milling of powder mixtures consisting of the alloying elements, master alloys and the oxide dispersion [1, 2]. The mechanically alloyed (MA) powder is compacted by extrusion to form bar or tube stock. With suitable heat treatments, the desired coarse elongated grain structure can be achieved.

The Ni and Fe based ODS alloys rely for their high temperature oxidation/corrosion resistance on the formation of slowly growing and strongly adherent chromia and alumina scales [5-7]. In the present paper, the oxidation properties of the most commonly used Fe and $\mathrm{Ni}$ based ODS alloys are presented. First, the behaviour of the most important commercially

(*) Keynote lecture. 
available ODS alloys are compared. Subsequently, the mechanisms of scale formation are illustrated using the $\mathrm{NiCr}$ and the $\mathrm{FeCrAl}$ based alloys as examples, because most information in the literature relates to these groups of ODS materials.

\section{Comparison of commercial ODS alloys.}

Table I shows the nominal compositions of a number of commercially available ODS alloys $[2,8,9]$. The Ni based material MA 754 and the FeCrAl based materials are strengthened by dispersion and solid solution hardening. MA 6000, PM 3030 and MA 760 are additionally strengthened by $\gamma$-prime and carbide formation.

Table I. - Nominal composition of some commercially available ODS alloys. The MA materials are supplied by INCO International, Hereford, UK; the PM materials by PM Hochtemperatur-metall, Frankfurt, FRG; the ODM material by Dour Metal, Dour, B.

\begin{tabular}{|c|c|c|c|c|c|c|c|c|c|c|}
\hline \multirow[t]{2}{*}{ Alloy } & \multicolumn{10}{|c|}{ Composition in Mass. $-q$} \\
\hline & $\mathrm{Ni}$ & $\mathrm{Fe}$ & Cr & Al & $T i$ & พ & Mo & $\mathrm{Ta}$ & c & $\mathrm{Y}_{2} \mathrm{O}_{3}$ \\
\hline MA 754 & Base & - & 20 & 0.2 & 0.3 & - & - & - & 0.04 & 0.5 \\
\hline MA 6000 & Base & - & 15 & 4.5 & 2 & 2 & 2 & 2 & 0.04 & 1.0 \\
\hline MA 760 & Base & - & 20 & 6 & - & 3.5 & 2 & - & 0.04 & 1.0 \\
\hline PM 3030 & Base & - & 17 & 6 & - & 3.5 & 2 & - & 0.05 & 1.0 \\
\hline MA 956 & - & Base & 20 & 4.5 & 0.3 & - & - & - & 0.04 & 0.5 \\
\hline PM 2000 & - & Base & 20 & 5.5 & 0.3 & - & - & - & 0.01 & 0.5 \\
\hline ODM 751 & & Base & 16 & 4.5 & 0.6 & - & 1 & - & 0.01 & 0.5 \\
\hline
\end{tabular}

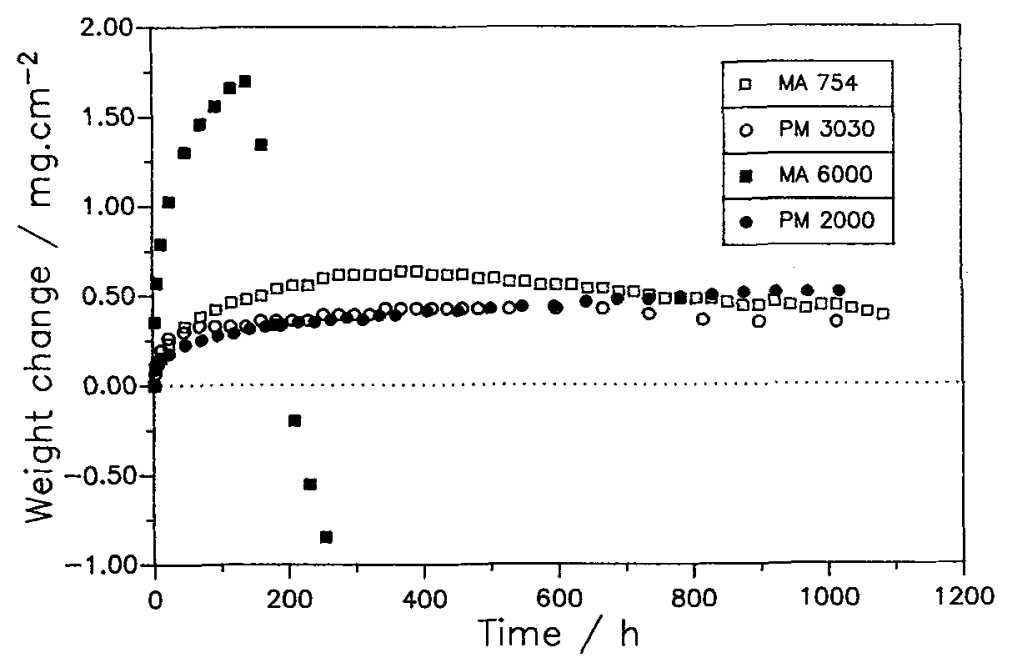

Fig. 1. - Comparison of the oxidation behaviour of various ODS alloys during cyclic oxidation in air at $1000^{\circ} \mathrm{C}$. 
Figure 1 shows weight change data during cyclic oxidation in air at $1000^{\circ} \mathrm{C}$, schematically illustrating the fundamental differences in oxidation behaviour between the various alloy types. The best behaviour was observed for the FeCrAl based alloys, due to formation of a slowly growing alumina surface scale which remained strongly adherent up to very long times. The chromia scales formed on MA 754 showed a higher growth rate, and scale spallation occured after longer exposure time. In spite of the relatively high aluminium content, the $\mathrm{NiCrAl}$ based alloy MA 6000 formed chromia rich oxide scales, with a growth rate which was clearly higher than that of the scale on MA 754. The reason for this was the presence of titanium, which is known to enhance the growth rates of chromia scales, leading to early spalling [10]. Due to the very low titanium content and an increased aluminium level, the alloys MA 760 and PM 3030 possess far better oxidation resistance than MA 6000, but are still inferior to the FeCrAl based alloys. Whereas the last mentioned alloys formed nearly pure alumina scales already in the very early stages of oxidation [11], MA 760 and PM 3030 exhibited quite a long period of transient oxidation during which the aluminium oxidized internally [10].

\section{Comparison with non-ODS alloys.}

The ODS alloy MA 754 showed significantly lower oxide growth rates and better spalling resistance than an yttria-free $\mathrm{Ni}-20 \mathrm{Cr}[12,13]$. In $\mathrm{MA} 754$, selective oxidation of chromium occurred, whereas the scale on $\mathrm{Ni}-20 \mathrm{Cr}$ contained significant amounts of $\mathrm{NiCr}_{2} \mathrm{O}_{4}$ and $\mathrm{NiO}$, in addition to chromia. In respect to spalling resistance, the effect of yttria on the oxidation behaviour of $\mathrm{FeCrAl}$ alloys was similar to that observed for the $\mathrm{NiCr}$ alloys: the scale adherence of the ODS alloy was far better than that of $\mathrm{Fe}-20 \mathrm{Cr}-5 \mathrm{Al}$ [12]. In respect to scale growth rate, however, the differences between the ODS and non-ODS alloy were far less pronounced than in the case of NiCr. The compositions of the scales on ODS and non-ODS FeCrAl alloys differ only slightly (see next section); in both cases, the surface scales consisted mainly of alumina and no spinel formation was detected.

The improvement in oxide scale properties imparted by the presence of the yttria dispersion was similar to that which can be obtained by small additions of metallic yttrium. Therefore, the cyclic oxidation resistance of MA 956 was as good as or slightly better than that of yttrium containing heating element alloys [5]. The advantage of adding yttrium in form of an oxide dispersion rather than metallic yttrium is, that, in the last mentioned case, internal oxides can form due to oxidation of Y/Al-containing compounds on alloy grain boundaries.

\section{Scale growth processes.}

Oxide scales on $\mathrm{NiCr}$ and FeCrAl based alloys grow by oxygen and metal transport, probably via grain boundaries [12]. Although the relative contribution of anion and cation transport to alumina and chromia scale growth is time and temperature dependent [10], the scales on the ODS alloys always show a significantly larger contribution of oxygen transport to scale growth, than do corresponding non-ODS alloys of the same base composition (Fig. 2). The change in growth process can explain the suppression of spinel formation in the case of $\mathrm{NiCr}$ alloys [12], and the differences in Fe and Cr distribution in alumina scales on ODS and nonODS FeCrAl based alloys [11] (Fig. 3). The Fe and $\mathrm{Cr}$ based oxides formed in the transient stages of oxidation are incorporated into the scale due to parallel anion and cation transport in the case of $\mathrm{Fe}-20 \mathrm{Cr}-5 \mathrm{Al}$. In the case of the ODS alloy, the oxides formed during transient 

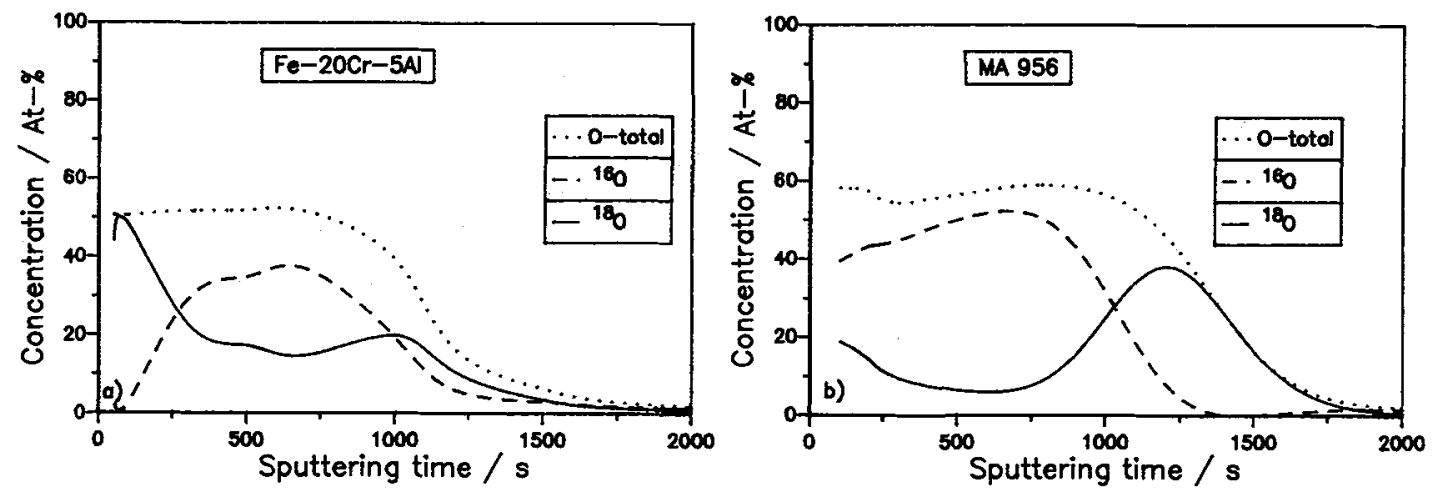

Fig. 2. - Oxygen isotope distributions in the scales on Fe-20Cr-5Al and MA 956 after two-stage oxidation (1st. stage: $2.5 \mathrm{hr}$ in air; $2 \mathrm{nd}$. stage: $5 \mathrm{hr}$ in ${ }^{18} \mathrm{O}$-enriched air) at $1000^{\circ} \mathrm{C}$ measured by SNMS [11].

$t_{1}$

\begin{tabular}{|c|c|c|c|}
\hline Alumina & $\begin{array}{l}\text { Fe-rich } \\
\text { oxide } \\
\text { IIIm]ा }\end{array}$ & $\begin{array}{l}\text { Cr-rich } \\
\text { oxide } \\
\bigotimes \otimes \bigotimes\end{array}$ & gas \\
\hline & & & alloy \\
\hline
\end{tabular}

$t_{2}$

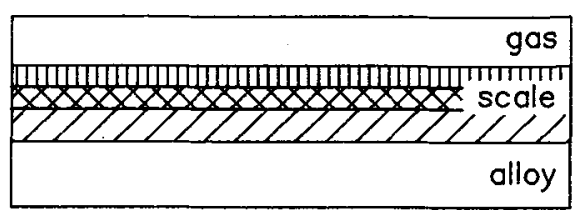

$\mathrm{Fe}-20 \mathrm{Cr}-5 \mathrm{Al}$

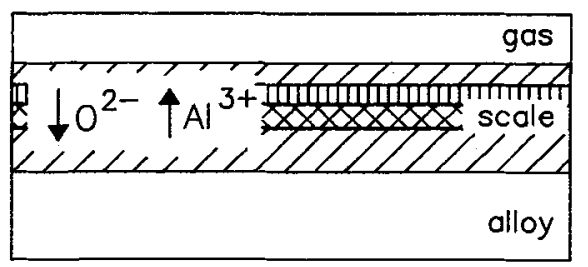

MA 956

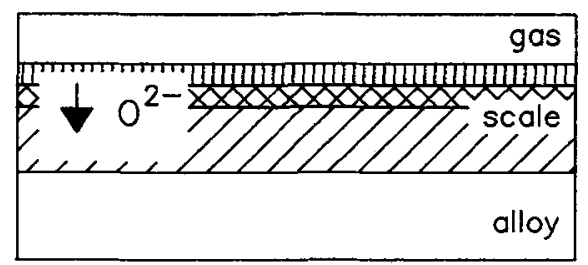

Fig. 3. - Effect of transport processes on the time dependence $\left(t_{1}<t_{2}<t_{3}\right)$ of the iron and chromium distribution in alumina scales on Fe-20Cr-5Al and MA 956 [11].

oxidation remain at the oxide surface. It has been claimed, that the change in growth process due to the presence of yttria is an important factor for the improved adherence of oxide scales on ODS alloys [5, 12-15].

Comparison of the scale transport phenomena determined after two-stage oxidation using ${ }^{18} \mathrm{O}$ tracer and examination of the resulting scale morphologies showed that for both ODS alloy types outward scale growth is not completely suppressed by the addition of yttria $[12,16]$. 
In the case of the FeCrAl alloys, limited outward growth occurs due to diffusion of elements such as titanium and yttrium through the alumina. The outward growth does not proceed evenly over the whole scale, but localized via rapid transport paths. This leads to the formation of small "nodules" of Y/Ti-containing oxides on top of the flat, inward growing alumina scale. In the case of MA 754, the amount of outward growth was much more pronounced and can easily be observed in scale cross sections after long time exposures (Fig. 4).
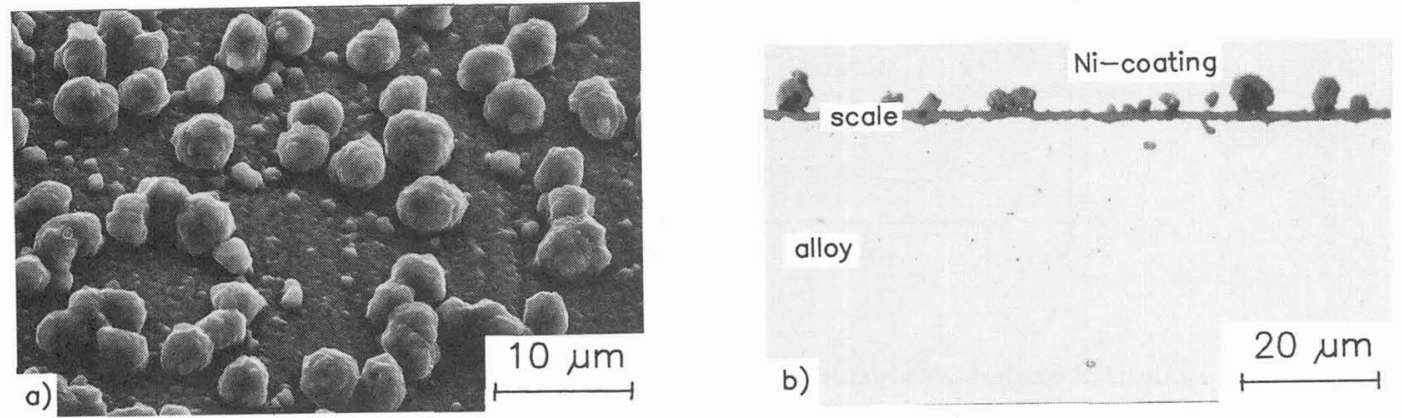

Fig. 4. - Nodule formation on the oxide surface of MA 754 [16]: a) scale morphology after $3 \mathrm{~h}$ oxidation at $1000^{\circ} \mathrm{C}$; b) scale cross-section after $300 \mathrm{~h}$ oxidation at $900^{\circ} \mathrm{C}$.

\section{Yttrium incorporation in the oxide scale.}

Although yttrium is present in ODS alloys in the form of a thermodynamically very stable oxide dispersion, several recent investigations showed that, together with titanium, it can diffuse quite easily in the alumina scale on MA 956 and in the chromia on MA 754, and becomes enriched at the oxide surface [17]. RBS analysis revealed that, in the case of MA 956, the yttrium surface enrichment increased with time (Fig. 5) and temperature, eventually leading to the formation of mixed Y/Ti-oxides at the alumina surface [18]. These mixed oxides could also be detected on alumina grain boundaries in scale cross sections [5]. Other investigators $[13,14]$ showed, by high resolution TEM studies, that yttrium tends to become enriched at chromia and alumina grain boundaries in the form of a segregated layer, rather than in the form of a compound. The incorporation of yttrium in the oxide grain boundaries has been claimed to be responsible for the changes in growth mechanisms [14] which were already discussed in the previous section.

\section{Effect of yttria content.}

As far as it is known to the author, only a few systematic studies have been made of the effect of yttria content on the oxidation behaviour of ODS alloys. In the early work by Michels [19], it was found that yttria additions of 0.2 and $1 \%$ decreased the oxidation rate of $\mathrm{Ni}-20 \mathrm{Cr}$, the higher yttria content showing the most significant decrease. A similar observation was made by Lawn et al. [20] who showed that $2 \%$ of yttria in ODS chromium gave better results 


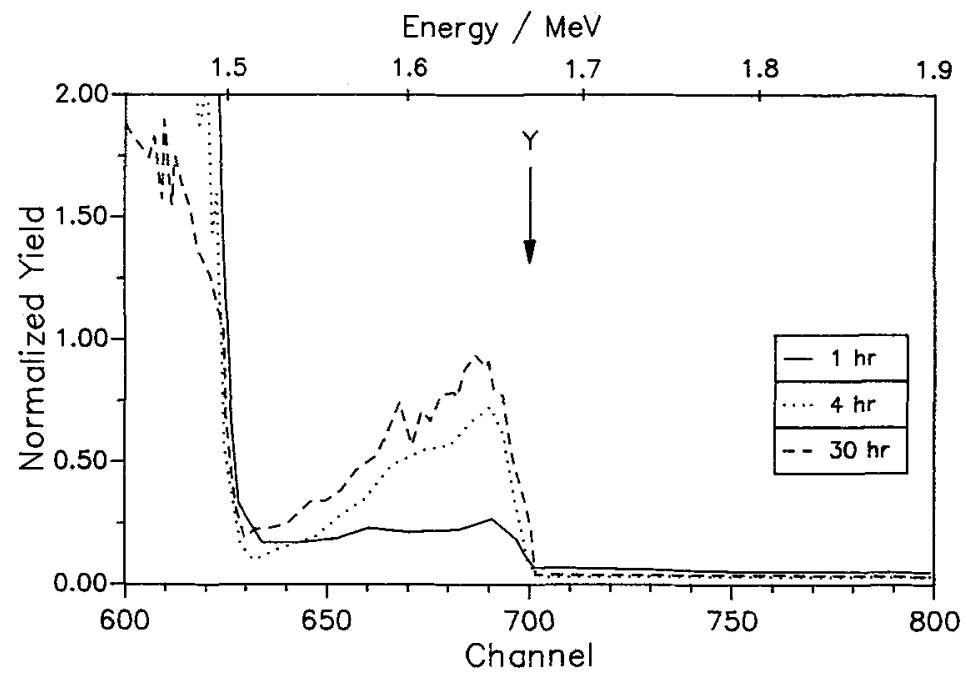

Fig. 5. - RBS analysis of oxide scales formed on MA 956 during oxidation at $1000^{\circ} \mathrm{C}$ showing increase of yttrium enrichment with increasing exposure time [18].

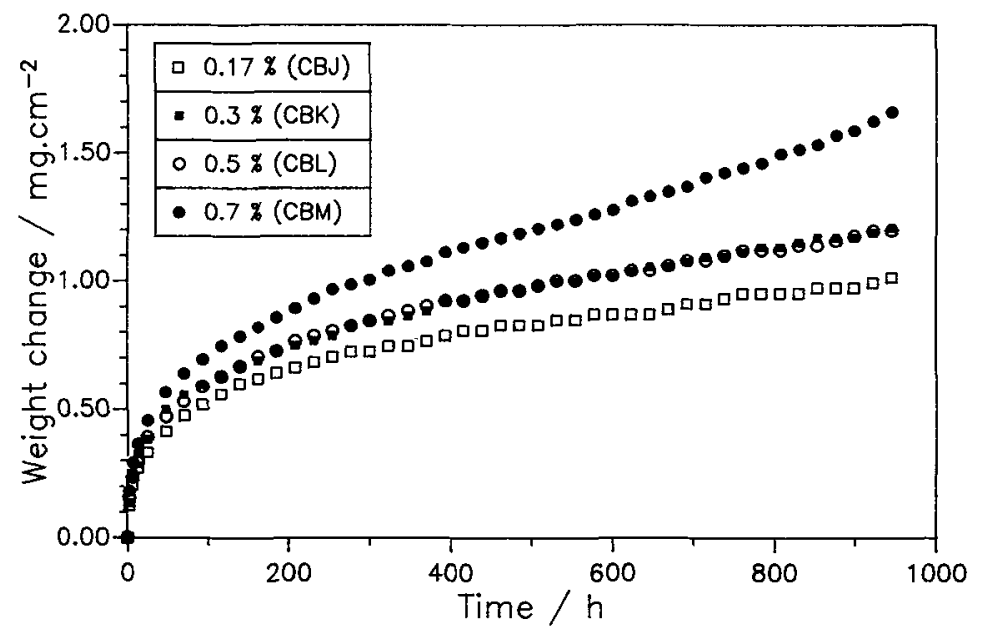

Fig. 6. - Effect of yttria content on oxidation rate of MA 956 during oxidation at $1100^{\circ} \mathrm{C}$ [18].

than $0.5 \%$. This can be explained by the incomplete suppression of cation diffusion in the chromia scales in the low yttria materials, as explained above.

Recently, the effect of variations in yttria content $(0.17-0.7 \%)$ on the oxidation behaviour of MA 956 in the temperature range $900-1200^{\circ} \mathrm{C}$ was studied [18, 21]. The lowest oxidation rates were observed for the alloy with the lowest yttria content (Fig. 6). Similar observations were obtained with alloys from the type PM 2000 [22]. A possible explanation for this yttria dependence is an enhancement of oxygen diffusion, due to a change in the oxide grain boundary density (Fig. 7). Experiments with two model FeCrAl based ODS alloys of the type 

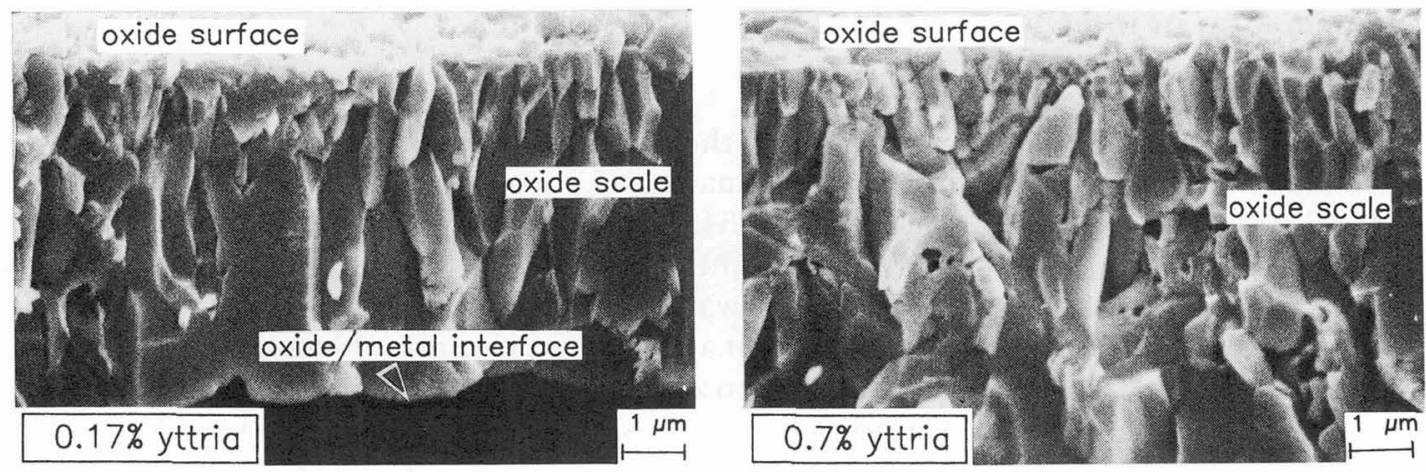

Fig. 7. - Effect of yttria content on oxide grain structure of MA 956 after $1000 \mathrm{~h}$ oxidation at $1100^{\circ} \mathrm{C}$.

ODM 331 (13\%Cr, $3 \% \mathrm{Al})$ containing 0.5 and $0.02 \%$ yttria showed only very slight differences in growth rates of the two alloys [22], in agreement with recent data from Bennett $e t$ al. [23]. After prolonged cyclic oxidation at $1100^{\circ} \mathrm{C}$ and $1200^{\circ} \mathrm{C}$, however, the low yttria alloy exhibited significant scale spallation, whereas the other material exhibited good scale adherence, similar to that of MA 956.

Two stage oxidation experiments with the ODM 331 alloys at $1100^{\circ} \mathrm{C}$, using an ${ }^{18} \mathrm{O}$ tracer, showed that the difference in oxidation mechanisms of the two alloys was similar to that described earlier for MA 956 and $\mathrm{Fe}-20 \mathrm{Cr}-5 \mathrm{Al}$; that is, the relative amount of cation diffusion in the scale on the alloy with $0.02 \%$ yttria was significantly larger than that on the alloy with $0.5 \%$ yttria [22].

\section{Effect of the dispersion type on oxidation behaviour.}

The few systematic studies available concerning the effect of dispersion composition on the oxidation behaviour have mainly concentrated on alloys of the type Ni-20Cr. The first to be developed NiCr based ODS alloys contained $\mathrm{ThO}_{2}$ as a dispersion [24, 25]. The presence of thoria enhanced the selective oxidation of chromium, and significantly decreased the growth rate of the scale. Similar effects were found for $\mathrm{CeO}_{2}$ additions in Fe-20 Cr [26]. Michels [19] studied the effect of various dispersions $\left(\mathrm{ThO}_{2}, \mathrm{Al}_{2} \mathrm{O}_{3}, \mathrm{Y}_{2} \mathrm{O}_{3}, \mathrm{La}_{2} \mathrm{O}_{3}, \mathrm{Li}_{2} \mathrm{O}\right)$ on the oxidation of $\mathrm{Ni}-20 \mathrm{Cr}$ in the temperature range $1000-1200{ }^{\circ} \mathrm{C}$. Except $\mathrm{Li}_{2} \mathrm{O}$, all other dispersions caused a similar reduction in the oxidation rate of the $\mathrm{NiCr}$ alloy, provided that the amount of dispersion was sufficiently high (around 1 weight \%). Nagai et al. [27, 28] studied the effect of various dispersions on the isothermal oxidation behaviour of $\mathrm{Ni}-15 \mathrm{Cr}$ and $\mathrm{Ni}-20 \mathrm{Cr}$. La, $\mathrm{Sm}, \mathrm{Gd}$ and $\mathrm{Y}$ oxide reduced the oxidation rate, whereas the effect of $\mathrm{Al}$ and $\mathrm{Ti}$ oxide was only slight. $\mathrm{Si}$ and $\mathrm{Cr}$ oxide dispersions increased the oxidation rate and increased spalling. Vazquez and Fulton [29] compared the effect of $\mathrm{HfO}_{2}$ with that of a $\mathrm{Y}_{2} \mathrm{O}_{3}$ dispersions on the oxidation behaviour of FeCrAl alloys. The positive effect of $\mathrm{HfO}_{2}$, which was similar to that of yttria, was attributed to doping of the alumina and a decrease in the oxide grain size. 


\section{Formation of internal porosity.}

An effect which has often been described in the context of long term oxidation studies with ODS alloys at high temperatures is the formation of porosity in the bulk material. In the case of the chromia forming material MA 754, porosity was found in the area beneath the oxide scale. Initially, this was attributed to the presence of argon incorporated in the alloy during the mechanical alloying process. It was found, however, [30] that this kind of pore formation was not specific for ODS alloys, but also occured in non-ODS materials of the same composition. The depth of the pore formation zone was clearly connected with the chromium depletion profile beneath the surface scale and was, therefore, attributed to the Kirkendall effect [30]. A similar type of pore formation was observed beneath the chromia based scales formed on MA 6000 during long time oxidation at $1000^{\circ} \mathrm{C}$ (Fig. 8) such pore formation occurred to a far lower extent beneath the alumina based scale on PM 3030 [10].
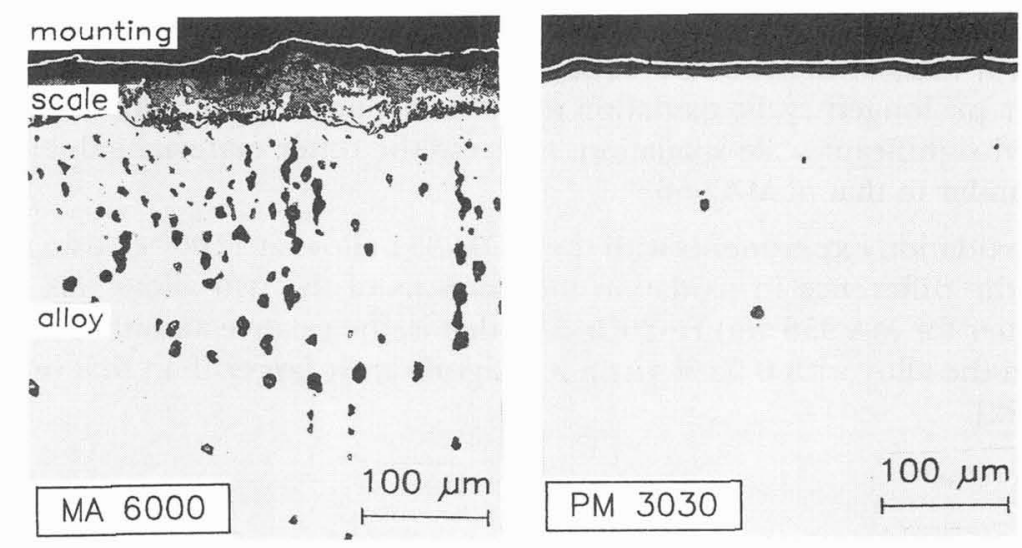

Fig. 8. - Difference in pore formation beneath surface scales of MA 6000 and PM 3030 after $1000 \mathrm{~h}$ oxidation in Air-1 vol. $\% \mathrm{SO}_{2}$ at $1000^{\circ} \mathrm{C}$.

Another type of internal porosity has been described for the FeCrAl based ODS alloys $[2,23]$. After high temperature exposure of these alloys, pores were found in the center of the specimen, whereas a pore-free zone was observed in the near surface region. An interesting observation is that this porosity did not occur in non-recrystallized, fine grained material [2], as far as the porosity can be detected with conventional optical microscopy and SEM. In the recrystallized material, the number of voids tended to decrease with increasing temperature, while void size increased [23]. The formation of the porosity did not depend on the atmosphere in which the alloys were exposed [23], nor on the gas in which the powders were milled during the mechanical alloying process [2]. Although, from present knowledge, there is no clear solution for preventing internal pore formation in FeCrAl based ODS alloys, Korb [2] proposed that, in any case the use of inert gas during milling, and incorporation of coarse oxide dispersions in the material should be avoided. 


\section{Summary.}

Yttria dispersion strengthened $\mathrm{NiCr}, \mathrm{NiCrAl}$ and $\mathrm{FeCrAl}$ based alloys are promising materials for application under demanding conditions of stress and corrosive environments. The materials are superior to non-ODS alloys of the same base composition in respect to selective oxidation of the scale forming element, scale growth rate, and scale adherence. Due to the presence of yttria, the alumina and chromia scales show a higher relative contribution of oxygen transport than do non-ODS alloys of the same base composition. This effect, which explains most of the observed changes in structural, chemical and protective properties of the scale due to yttria additions, is attributed to the incorporation of yttria in the oxide scale, especially on grain boundaries. Although similar positive effects can be obtained with oxide dispersions other than yttria, the available literature data indicate no clear alternative to yttria. From the viewpoint of oxidation resistance, the amount of yttria dispersion in the commercially available ODS alloys does not seem to be at an optimum level. In the $\mathrm{NiCr}$ based alloys, higher yttria contents seem to be required for optimum oxidation properties; in the FeCrAl based materials, lower amounts than the usual value of $0.5 \%$ are expected to be beneficial. Further development of the tedious ODS alloy fabrication process is expected to lead to a further improvement in materials properties, and to better fabrication reproducibility of ODS alloys, thereby extending the field of potential applications for this class of materials.

\section{Acknowledgements.}

The author is grateful to his colleagues at the Research Centre Jülich for their assistance in carrying out the experimental studies and for their stimulating discussions during the progress of this work. 
[12] Quadakkers W.J., Holzbrecher H., Briefs K.G., BeSke H., Oxid. Met. 32 (1989) 67.

[13] Ramanarayanan T., Ayer R., Petkovic-Luton R., Leta D.P., Oxid. Met. 29 (1988) 445.

[14] Przybylski K., Yurek G.J., Symp. of High Temp. Mater. Chem. IV (Honolulu, Hawaii, 1987) The Electrochemical Society (Pennington, NJ, USA).

[15] Ramanarayanan T.A., Ayer R., Petkovic-Luton R., J. Electrochem. Soc. 131 (1984) 923.

[16] Quadakkers W.J., SPEier W., Holzbrecher H., Nickel H., Conference Microscopy of Oxidation, proc. (Cambridge, UK, 26-28 March, 1990) p. 258.

[17] Bennett M., Houlton M., Conf. High Temp. Mat. for Power Engng., Kluwer Dordrecht, NL (Liege, B, 24-27 Sept. 1990) p. 227.

[18] Nickel H., Quadakkers W.J., First Int. Conf. Heat Resistant Materialś, proc. (Fontana, Wi, USA, 23-26 Sept. 1991) p. 87.

[19] Michels H.T., Metall. Trans. 7A (1976) 379.

[20] LAWN R.E., WILSON F.G., DESFORGES C.D., J. Less-Common Met. 58 (1978) 107.

[21] QUADAKKERS W.J., SCHMIDT K., GRÜB MEIER H., WALlURA E., Materials at High Temperatures 10 (1992) 23.

[22] Clemens D., Quadakkers W.J., Research Centre, Conference Angewandte Oberflächenanalytik (Jülich, Germany, June 1992) Proceedings in Fresenius J. for Analyt. Chemistry, in press.

[23] BENNETT M.J., First Int. Conf. Heat Resistant Materials, proc. (Fontana, Wi, USA, 23-26 Sept. 1991) p.95.

[24] STRinger J., Hed A.Z., WAllWORK G.R., Wilcox B.A., Corros. Sci. 12 (1972) 625.

[25] Grgains C.S., PETTIT F.S., Metall. Trans. 2 (1971) 1071.

[26] Rhys-Jones T., Grabke H., Kudielka H., Corros. Sci. 27 (1987) 49.

[27] NAGAI H., OKABAYASHI M., Trans. Jpn Inst. Met. 22 (1981) 101.

[28] NaGai H., Koshi-Ishi F., IshikaWA S., Shoji K., Trans. Jpn Inst. Met. 24 (1983) 839.

[29] Vazquez J., Fulton L., Conf. Perf. of High Temp. Mat. in Fluidized Bed Combustion Systems and Process Industries (Cincinnati, Ohio, USA, Oct. 10-15 1987) p. 137.

[30] Rosenstein A., Tien J., Nix W., Metall. Trans. 17A (1986) 151. 